\title{
A VIOLÊNCIA DO ORDÁlIO CONTRA A MULHER SUSPEITA DE ADULTÉRIO EM NM 5,11-31
}

The Violence of Ordeal Against Women Suspected of Adultery in Num 5,11-31

Vicente Artuso *

RESUMO: A relevância do artigo está na análise do ritual do ordálio em Nm 5,1131 que evidencia as formas de violência contra a mulher. A abordagem do texto se serve da hermenêutica de gênero: masculino-feminino. Ela se mostra apropriada no contexto sociorreligioso patriarcal e androcêntrico da época. Assim, o objetivo do estudo é realçar a ideologia do ritual do ordálio que legitima a discriminação e práticas de violência contra a mulher. Percorre-se os passos seguintes: introdução, contexto e objetivo do relato no Livro dos Números, tradução, estrutura, análise dos personagens e das ações e hermenêutica. Resulta desse estudo uma visão mais realista da situação da mulher suspeita de adultério, pois mediante o ordálio ela é submetida a um risco interpretado como castigo, caso ela seja culpada de infidelidade. De vítima acusada sem provas ela é tornada culpada. $\mathrm{O}$ artigo conclui que a violência narrada serve de controle seguro dos corpos das esposas por parte dos maridos ciumentos. Essa leitura crítica desautoriza a forma do julgamento mediante o ordálio, existente também em outras culturas do Antigo Oriente.

PALAVRAS-CHAVE: Ordálio. Mulher. Violência. Julgamento. Sacerdote.

ABSTRACT: The relevance of the article lies in the analysis of the ritual of the ordeal in Num 5,11-31, which highlights the forms of violence against women. The text uses the hermeneutic male/female approach to gender, appropriate to the patriarchal and androcentric socio-religious context of the time. Thus, the study aims to highlight the ideology of the ordeal ritual that legitimizes discrimination and practices of violence against women. The following steps are taken: introduction,

* Pontifícia Universidade Católica do Paraná, Curitiba, Paraná, Brasil. 
context and purpose of the report in the book of Numbers, translation, structure, analysis of characters and actions and hermeneutics. This study results in a more realistic view of the situation of a woman suspected of adultery, as, through the ordeal, she is subjected to a risk interpreted as punishment if found guilty of infidelity. From alleged victim, she becomes the guilty one. The article concludes that the narrated violence serves as a strict control of the wives' bodies by their jealous husbands. This critical reading disallows the form of judgment through the ordeal, which also exists in other cultures of the Ancient East.

KEYWORDS: Ordeal. Woman. Violence. Judgment. Priest.

\section{Introduçãa $o^{1}$}

$\mathrm{O}$ ritual chamado "ordálio" é uma prova judiciária, em geral, com o objetivo de comprovar a culpa ou a inocência dos acusados. Nesse caso, a mulher acusada de infidelidade era submetida a um risco interpretado como castigo vindo de Deus. Aplicava-se quando as provas da culpa contra o acusado ou acusada mostravam-se insuficientes. Assim, o ordálio visava solicitar o veredicto vindo de Deus em relação à veracidade da declaração da mulher (MIGLIO, 2010, p. 229; CARDELLINI, 2013, p. 243). A prática do ordálio é prescrita no antigo código de Hammurabi (séc. XVIIIa.C.). Consta que a mulher suspeita de adultério, como também a pessoa acusada de feitiçaria, era lançada no rio: se sobrevivesse, era inocente; se morresse era culpada. Assim, o julgamento final era atribuído a Deus. Narrações de casos de ordálio semelhantes se encontram também em Mári (séc. XVIII a.C.). Nesses escritos, o ordálio era a forma de encontrar uma solução definitiva em questões disputadas. A água era misturada com poeira ou sujeira, então as partes em conflito faziam um juramento e em seguida bebiam essa mistura; a quem a bebida fizesse algum mal, esse perdia a questão (MARFO, 2017, p. 162; PRITCHARD, 1969, p. 632). Ordálios se encontram em outras culturas, com formas bem variadas, como é, por exemplo, a prova do veneno comum entre povos africanos (LÉVY-BRUHL, 2008, p. 220-221).

Na Idade Média, aos poucos, a prática foi desaparecendo. Agobardo, Arcebispo de Lião (760-840), assegurou que Deus, apesar de Onipotente, tem desígnios secretos que não são revelados por meio do ordálio da água fervente, ou do ferro em brasa, ou de combates cruéis (FERRASIN, 2011, p. 13). Aos poucos, os sistemas jurídicos evoluíram para procedimentos mais racionais (FERRASIN, 2011, p. 7), e a crença de que os resultados

\footnotetext{
${ }^{1} \mathrm{O}$ artigo é resultado de projeto de pós-doutorado realizado em 2019-2020 no Programa de Pós-Graduação em Ciências da Religião da Universidade Metodista de São Paulo, sob a supervisão do Prof. Dr. Ademar Kaefer.
} 
do ordálio eram oriundos de um veredicto divino foi perdendo força. A pesquisa se ocupa de um relato de ritual de ordálio, ainda considerado sagrado, sem paralelos no contexto bíblico e diferenciado pela violência na forma de sua aplicação e nos seus efeitos no corpo da mulher.

Reconhece-se nos relatos antigos de ordálio que os juízos de Deus eram manipulados pelos poderosos para legitimar práticas opressoras. $\mathrm{O}$ antigo texto de Nm 5,11-31, do séc. VI a.C., requer uma análise com essa ótica crítica para perceber a ideologia na instituição de um ritual sagrado. $\mathrm{O}$ propósito do estudo é verificar os efeitos danosos do ordálio no corpo da mulher, e como a violência física e moral contra a mulher se justificava naquele contexto ainda patriarcal. Em vista disso, metodologicamente, analisa-se o texto com a categoria básica da hermenêutica feminista da dominação sobre as mulheres, do androcentrismo e sexismo (SCHOTTROFF; SCHOROER; WACKER, 2008, p. 49-51). Com essa análise a partir da pessoa acusada e do clamor por justiça, desautoriza-se o julgamento. Para esse escopo, dar-se-á atenção especial a expressões e detalhes estilísticos do relato em que se possa identificar como o ritual do ordálio reforça o controle patriarcal sobre a mulher (BRITT, 2007, p. 1). Pretende-se, outrossim, mostrar os avanços na interpretação com o olhar voltado para a situação da mulher e também para a violência da instituição do ordálio pouco observados na exegese histórico-crítica.

\section{Contexto e objetivo no livro dos Números}

Tomando-se distância do texto delimitado, é importante verificar sua posição no contexto literário das caminhadas e paradas do povo de Israel até chegar à terra prometida, como é narrado no livro do Exodo e Números. Isso ajuda a compreender os motivos dos autores inserirem o relato do ordálio no livro dos Números. Pois bem, a perícope de Nm 5,11-31 faz parte de um bloco de diversas leis e rituais ( $\mathrm{Nm} 5,1-6,27$ ), situado na parada do Sinai, na primeira parte do livro dos Números (Nm 1,1-10,10) (LEVINE, 2000, p. 121). A introdução da frase: Falou o SENHOR a Moisés repetida no Livro dos Números (Nm 1,1; 2,1; 3,5.11.14.40.44; 4,1.17.21; 5,1.5.11; 6,1.22), geralmente indica o início de nova ação e também a conexão do livro dos Números com o resto do Pentateuco (MARFO, 2017, p. 152, nota 30). A redação situa-se no período pós-exílico, quando a comunidade dos filhos de Israel tenta resgatar sua identidade com base na observância da lei recebida por Moisés. Nm 5,11-31 seria, então, uma retroprojeção da organização da comunidade judaica pós-exílica para o período da parada no Sinai. Do ponto de vista literário, todos esses textos narrativos e antigos textos legislativos visam a preparação da comunidade para a partida do Sinai até Moab (Nm 1,1-10,10). São, em geral, regras de pureza do acampamento e pureza do povo. 
Para De Vaulx (1972, p. 89), esse bloco legislativo de tradição sacerdotal é dividido entre as seguintes regras: acerca da expulsão do leproso do acampamento (Nm 5,1-4); acercada reparação de danos ao próximo (Nm 5,5-10); acerca do ordálio do ciúme aplicado à mulher suspeita de adultério (5,11-31); acercado nazireato (Nm 6,1-21) e, concluindo, com a bênção de Aarão (Nm 6,22-27). De acordo com Wenham (1985, p. 86), a associação da ofensa com ofertas pela culpa serve para ligar estas três seções de $\mathrm{Nm}$ 5,5-10; 5,11-31; 6,1-21. Segundo Fishbane (1974, p. 26), esse corpus de práxis rituais se encontra num contexto mais amplo entre $\mathrm{Lv} 1,1$ e a bênção de Aarão em Nm 6,22-27, emoldurado com a informação da construção finalizada do Tabernáculo do deserto (Ex 40,33; e Nm 7,1). A inserção de Nm 5,11-31 nesse contexto sacerdotal justifica-se pela atuação do sacerdote. $\mathrm{O}$

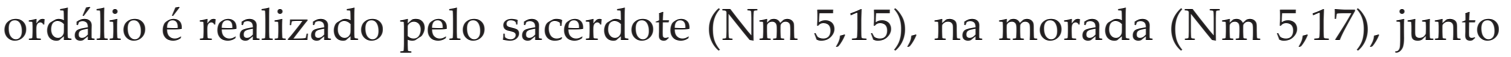

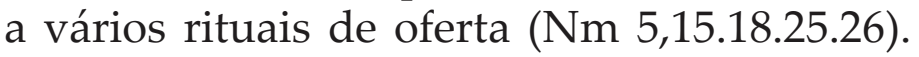

Assim, essas regras de pureza, como outras no contexto sacerdotal, reafirmam que Israel no deserto é povo eleito e que precisa se purificar para prosseguir a marcha. Nessa visão, a infidelidade é considerada uma impureza. E toda dúvida sobre a culpa ou inocência da mulher denunciada deve ser redimida em vista da purificação, pois Israel é uma comunidade cultual em marcha. Quando Mirian se achava leprosa, portanto, impura, a comunidade dos filhos de Israel permaneceu na espera. Só retomou a marcha quando teve certeza de que ela ficara purificada da lepra para que pudesse ser reintegrada na comunidade (Nm 12,11-15). No caso de Nm 5,11-31, a suspeita de adultério devia ser esclarecida em vista da purificação de toda a comunidade. Aqui, entende-se a insistência e repetição do vocabulário sobre puro e impuro. Essa é a interpretação relacionada com o texto dos Números na sua forma final como foi estabelecido. Porém, quem lê essa perícope isolada não ficará satisfeito com essa interpretação. Há necessidade de analisar o texto num contexto socio-histórico, mediante métodos e abordagens que ajudem na interpretação à luz de outra cultura muito diferente daquela época. Convém voltar o olhar no texto para seu conteúdo e forma, para depois interpretá-lo.

Apresenta-se a tradução literal do texto hebraico com maior preocupação em certos detalhes do estilo, nem sempre observáveis nas edições atuais da Bíblia em português

${ }^{11} \mathrm{E}$ o SENHOR ${ }^{2}$ falou a Moisés dizendo: ${ }^{12 “} \mathrm{Fala}$ aos filhos de Israel e lhes dirás: 'Se um homem' ${ }^{3}$, cuja mulher se afasta ${ }^{4}$ e comete uma traição contra ele, ${ }^{13}$ visto

\footnotetext{
${ }^{2}$ Optou-se traduzir o tetragrama sagrado יְוָּ (YHWH) - "SENHOR" em respeito àquela tradição de não pronunciar o nome sagrado própria do povo judeu.

${ }^{3}$ No hebraico, aparecem juntos o termo "homem" duas vezes. Nesse caso, como em outros, um deles significa o pronome indefinido: traduz-se geralmente: "algum homem", "qualquer homem".

${ }^{4} \mathrm{O}$ verbo (tistheh), aqui no imperfeito Qal, significa afastar-se, extraviar-se, ser infiel em relação à mulher casada $(\mathrm{Nm} 5,12.19 .20 .29)$. O tratado do Sothah, na Mixna, tratará com mais detalhes os casos de suspeita de infidelidade.
} 
que escondida dos olhos de seu marido um homem deitou-se com ela, havendo ejaculação de sêmen, e ela tornou-se impura, sem testemunha contra ela e sem ser agarrada em flagrante, ${ }^{14}$ entretanto, se atravessar sobre o marido um espírito de ciúme e se tornar ciumento de sua mulher que se tornara impura, ou ainda, se atravessar nele um espírito de ciúme e se tornar ciumento de sua mulher, que não se tornara impura: ${ }^{15}$ tal homem fará vir sua mulher até o sacerdote e trará a oferta dela em favor dela própria: um décimo do efá de farinha de cevada. Não derramará sobre ela azeite e não colocará sobre ela incenso, porque ela será uma oferta de ciúme. Será uma oferta de memorial, uma lembrança da ofensa.

${ }^{16} \mathrm{O}$ sacerdote fará aproximar-se a mulher e a fará permanecer diante do SENHOr. ${ }^{17} \mathrm{O}$ sacerdote tomará águas santas em um recipiente novo. Então o sacerdote tomará do pó que está no pavimento da morada e colocará na água. ${ }^{18} \mathrm{E}$ o sacerdote fará a mulher manter-se em pé diante do SENHOR e ele deixará soltar os cabelos ${ }^{5}$ da mulher, entregará nas palmas das mãos dela a oferta do memorial, oferta de ciúmes. E na mão do sacerdote estarão as águas da amargura ${ }^{6}$, que amaldiçoam. ${ }^{19}$ Então o sacerdote a fará jurar e dirá para a mulher: Se nenhum homem deitou contigo e se não te afastaste pela impureza enquanto sob o poder de teu marido, sê livre das águas amargas que amaldiçoam. ${ }^{20}$ Mas, se tu, quando te afastaste enquanto estavas sob o poder de teu marido, e que te tornaste impura e algum homem afora de teu marido se deitou contigo... ${ }^{72}$ Aqui o sacerdote fará a mulher jurar com juramento de maldição. O sacerdote dirá para a mulher: O SENHOR te entregue por maldição e por juramento no meio de teu povo. Quando o SENHor entregar tua coxa caindo 8 e teu ventre estiver inchando-se, ${ }^{22}$ entrarão estas águas que amaldiçoam em tuas entranhas para incharem o ventre e para que caia a coxa. A mulher dirá: Amém! Amém! ${ }^{23} \mathrm{O}$ sacerdote escreverá essas maldições no livro, lavará nas águas amargas ${ }^{24}$ e fará a mulher beber das águas amargas que amaldiçoam. Entrarão nela as águas que amaldiçoam e se tornarão amargas. ${ }^{25} \mathrm{O}$ sacerdote tomará da mão da mulher a oferta dos ciúmes, agitará ${ }^{9}$ a oferta diante do SenHor e a

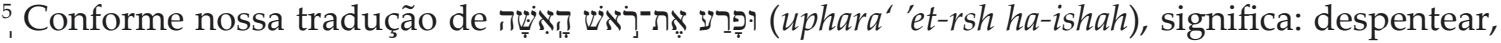
andar despenteado, com cabelos soltos (Lv 10,6; 13,45; 21,10). Assim, Ashley (1993, p. 118); Harrison (1992, p. 110) entre outros. A proposta da Setenta e da Vulgata, adotada também por Cardellini (2013, p. 211) é "descobrir a cabeça da mulher".

${ }^{6}$ Nesse caso o adjetivo é acrescentado no genitivo: "águas da amargura". Esperar-se-ia simplesmente "águas amargas", em que o adjetivo tem valor atributivo. Porém, conforme Gesenius e Kautzsch (1910, p. 128s), não é infrequente o uso idiomático da construção pela qual adjetivos são acrescentados no genitivo assumindo o valor de substantivos. Trata-se, portanto, de águas que são amargas em que a amargura pode ser predicada: águas são amargas, isto é, águas que são amargas (Is 28,1: flor murcha; 28,4: flor que murcha). Isso porque, potencialmente, produzem danos, o que é reforçado pelo particípio piel: "que amaldiçoam" - הַמְאמִרִרים (hame'ararim).

${ }^{7}$ De um longo período hipotético de orações condicionais dependentes, o texto apresenta uma descontinuidade, uma ruptura. Esperar-se-ia a frase principal para completar o período. Subentende-se aqui que aconteça o contrário do que é dito na apódose do v. 19b (CARDELLINI, 2013, p. 212, nota 53). Isso pode indicar a presença de fontes diferentes justapostas.

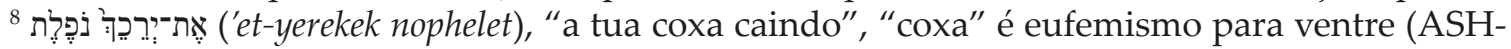
LEY, 1993, p. 118) e cair a coxa da mulher pode significar, nesse texto, um possível aborto. ${ }^{9}$ A forma verbal וְהָגניף (wehenîph), perfeito hifil com waw, traduzido como "agitará", indica o rito da "tenufa" que era um gesto de agitar ritualmente uma oferta diante do Senhor. Era
} 
oferecerá no altar. ${ }^{26} \mathrm{O}$ sacerdote tomará um punhado da oferta rememorativa dela e queimará no altar. Depois fará a mulher beber das águas. ${ }^{27}$ Fará beber das águas e acontecerá que, se ela se tornou impura, se cometeu uma traição contra o marido dela, entrarão nela as águas que amaldiçoam, que se tornaram amargas, e o ventre dela inchará, e as coxas dela cairão. A mulher se tornará maldição no meio de seu povo. ${ }^{28} \mathrm{E}$, se a mulher não se tornou impura, então ela será limpa. Será, então, inocente e conceberá uma descendência. ${ }^{29}$ Essa é a instrução dos ciúmes, quando uma mulher, sob o poder de seu marido, afastar-se e se tornar impura, ${ }^{30}$ ou quando atravessar sobre ele um espírito de ciúme e causar ciúme à sua mulher, fará comparecer a mulher diante do SENHor e o sacerdote lhe fará essa instrução. ${ }^{31} \mathrm{O}$ homem ficará livre da ofensa, mas aquela mulher carregará a ofensa dela'"'.

\section{Estrutura}

Os estudos diacrônicos mostram que o texto do Livro de Números pode ser considerado um texto compósito com estratos literários de diferentes épocas, porém deve-se reconhecer os limites desses métodos mais atentos às rupturas e incongruências do que ao estilo e elementos de unidade do texto (ARTUSO, 2012, p. 295). A estrutura de Cardellini (2001, p. 470475), aqui proposta, com poucas adaptações, revela uma unidade temática em torno do julgamento, com ações preponderantes do sacerdote e do homem e, conquanto a mulher é a mais citada, é também a mais calada. A característica de ritual sagrado aparece na moldura como palavra do SEnHor revelada a Moisés (v. 11.12), no início, e a institucionalização do rito diante do SENHOR (v. 30).

Ela explicita o conteúdo do texto e destaca as violências contra a mulher:

- 1 - Introdução: inicia com a palavra revelada do SENHor a Moisés (v.11-12a). Isso caracteriza bem o texto como sagrado;

- 2 - Definição do tema (vv. 12b-13 - início da prótase): a mulher de um homem comete adultério expresso em quatro modos diferentes (transviamento, infidelidade, relação com outro homem, contaminação). O fato não é provado e a falta de provas também é expressa de quatro modos (ignorância do fato por parte do marido, ocultação do fato, falta de testemunhos, falta do flagrante);

- 3 - Apresentação do caso (v. 14): o ciúme do marido e suspeita de adultério;

também gesto de oferecimento. Antigas versões divergem propondo traduzir com outros verbos e sempre no futuro: A Setenta traduz "porá"; Targum e a Vulgata "elevará", a Siríaca "oferecerá" (CARDELLINI, 2013, p. 214, nota 64). 
- 4- Procedimento do ordálio: preparação e realização da oferta (v. 1526), mediante o sacerdote;

- Cardellini (2001, p. 475) divide o corpo do texto em quatro atos:

- Ato $\mathrm{n}^{\mathbf{0}}$ 1: (v. 15) - início da apódose-ação do marido de conduzir a esposa ao sacerdote;

- Ato $\mathrm{n}^{\mathrm{o}}$ 2: (v. 16.17.18) - ação do sacerdote: colocação da mulher diante do SENHOR;

- Ato $\mathrm{n}^{\mathrm{0}}$ 3: (v. 19-24) -palavras do sacerdote dirigida à mulher sob Juramento;

- Ato no 4: (v. 25-26) - realização: oferta diante de SENHor e o ordálio;

- 5 - Consequências do ordálio: violência contra a mulher (v. 27-28):

o se culpada: seu ventre vai inchar e suas coxas cair.

o se inocente: será livre e conceberá uma descendência.

- 6 - Epílogo (v. 29-31) - Norma para o caso de suspeita de infidelidade, com esclarecimento sobre a culpa. Cardellini (2001, p. 475) vê a conclusão do texto no v. 30 e considera v. 31 como um esclarecimento à parte. Em nossa visão, esse versículo que condena a mulher é essencial para perceber a ideologia sacerdotal androcêntrica que justifica a instituição do ordálio como instrução vinda de Deus $(\mathrm{Nm} 5,29)$.

\section{Análise dos personagens e ações no ordálio}

Na narrativa do ordálio os atores principais são o sacerdote e o homem (marido). A mulher é citada, mas permanece passiva, sendo guiada pelos homens. Deus é citado na fala do sacerdote (v. 21) e do narrador (v. 1.30), o que caracteriza o caráter sagrado do rito. Essa análise dos personagens e suas funções ao longo do relato revela traços de uma cultura de submissão da mulher também legitimada num ritual religioso institucionalizado.

\subsection{A mulher no ritual do ordálio}

אֵָׁ ('ishah) aparece 19 vezes no ritual (Nm 5,12.14.15.18.19.21.22.24.25.26.27. 28.29.30.31); das quais cinco vezes aparece com sufixo de terceira pessoa, masculino, singular: "mulher dele", "sua mulher"; três vezes aparece citada enquanto sob poder do marido (v. 19.20.29); isso mostra sua dependência, pois o ritual composto por causa da suspeita de adultério da mulher é chamado comumente "o caso de sothah". A mulher é citada no texto enquanto está sob autoridade do marido (v.13) e destinada ao julgamento como culpada de cometer uma traição contra o homem (marido). Ela se contaminou, tornou-se impura. Como se menciona acima, nas vezes em que aparece 
citada, é com sufixo de terceira pessoa, masculino, singular: isto é, mulher do marido. No v. 14, aparece duas vezes "sua mulher" como propriedade, objeto de ciúme do marido. No v. 15, nessas condições, ela é conduzida ao sacerdote e a oferta do ciúme é para lembrar a culpa. Nos vv. 16 e 18, a mulher é conduzida pelo sacerdote a se postar diante do SENHor. Há, aqui, um detalhe, em que o sacerdote solta os cabelos da mulher e depois coloca nas suas mãos a oferta do ciúme, enquanto nas mãos do sacerdote está o instrumento que desencadeia o juízo: as águas amargas que amaldiçoam. Nos vv. 19 e 21, ela precisa jurar e vai ouvir do sacerdote que the fala das terríveis consequências do ordálio: se culpada, além dos danos físicos, ela é entregue à maldição no meio da comunidade (v. 21.27). Destaca-se que a mulher poderá falar a primeira vez e responder: "Amém! Amém!" (v. 22).

Nos vv. 24.26.27, novamente o sacerdote deve intervir e fará a mulher beber as águas amargas. A postura da mulher é passiva, ela tem nas mãos a oferta do ciúme, mas quem oferece a Deus é o sacerdote (v. 25). Ele fará a queima da oferta rememorativa (v. 26a) e depois fará a mulher beber da água amarga (v. 26b). As águas entrarão no corpo da mulher que sofrerá os efeitos da amargura. Os vv. 29.30 relembram a instrução do ciúme como direito do marido de conduzir a mulher diante do $\mathrm{SE}_{\mathrm{E}}$ NHOR para realizar o ritual. Ao final o ritual conclui-se: aquela mulher carregará a sua culpa (v. 31). Observa Wenham (1985, p. 86) que tanto o adultério quanto as ofensas narradas em $\mathrm{Nm}$ 5,11-31 são descritos como ofensas (v. 6), infidelidade (v. 12), contaminação (v. 27). A purificação da mulher também era prática que mantinha a mulher na dependência. As esposas adúlteras são escolhidas para merecerem atenção especial, porque o adultério polui as pessoas envolvidas, tornando-as impuras (v. 13.14.19.20.28.29; Lv 18,20.25.27).

A mulher é a única necessitada de purificação e forçada a tudo aceitar, pois não há oportunidade explícita de se mover ou falar. Ela apenas bebe a carta que contém o teor do julgamento (BRITT, 2007, p. 3). A mulher bebe a água e bebe junto a sentença da maldição. Segundo Mary Douglas (2001, p. 219), "é surpreendente que embora seja o ordálio a estabelecer a sua culpa ou inocência, ela é tratada como culpada sem o veredicto do ordálio". Ela é colocada em pé diante de SENHOR, conduzida pelo sacerdote, com cabelos soltos, com uma oferenda em suas mãos; não se move por si mesma; ela é tratada pelo homem como um manequim vivo. No entanto, o seu corpo fala. Mais adiante Britt $(2007$, p. 3) completa: "Como Ezequiel, que se torna profeta quando come o rolo contendo palavras de lamentação, a mulher adquire um mântico poder (Ez 2,10; 2,8), seu corpo fala, o qual declara inocência ou culpa, une sentença e punição numa única ação". A repercussão do fato fala mais alto que o relato. O clamor de corpos sofridos ecoa pelos tempos. Por isso, a hermenêutica do texto precisa focalizar o personagem central: a mulher que não age e se movimenta dirigida pelo homem. 


\subsection{O marido ciumento e a origem do julgamento}

Como motivo do ordálio bastou o ciúme do marido. Ele levanta a suspeita na mulher, mesmo sem provas concretas. Seja que ela tenha se tornado impura ou não, o que importa é um dado subjetivo: "se atravessar no marido um espírito de ciúme e se tornar ciumento" (v. 14). Comenta Cardellini: "O espírito de ciúme, com forte conotação emotiva indica o tormento do marido, sua inquietude em relação à esposa suspeita de infidelidade" (2013, p. 243). O ciúme do marido se torna base legal para o julgamento e para a própria lei. Comentam Knierim e Coats (2005, p. 79) que não é um possível ato de infidelidade da mulher que desencadeia o processo judicial, mas sim o ciúme. A lei, portanto, diz respeito ao caso do ciúme do marido sobre a possibilidade do ato de adultério. Por este motivo, também a expressão "oferta do ciúme" (v. 15.18.25) deve ser interpretada como uma oblação "oferta de memorial" que evoca a dúvida tormentosa do marido. Essa dúvida tem que ser esclarecida pelo ordálio, que se torna um ritual de julgamento, uma prova, seja da inocência, seja da culpa da mulher. Esse poder judiciário é dado ao sacerdote. Se olharmos ao aspecto do ciúme, a motivação do ordálio com oferta de farinha será por causa do marido e não da mulher, uma vez que a instituição do casamento era rigorosamente protegida pela categórica proibição do adultério (Ex 20,14; Dt 5,17) (FISHBANE, 1974, p. 25, 37). Aqui é estranha a harmonização de dois diferentes casos: uma alegação de infidelidade conjugal aparentemente substancial, porém, a mulher não foi vista nem apanhada em flagrante; uma alegação de infidelidade conjugal baseada na suspeita pura e simples. Não se observa justificação razoável para essa alegação tornada lei do ciúme (FISHBANE, 1974, p. 35).

\subsection{Ação do marido: apresentação da oferta (v. 15)}

No Código de Hammurabi, prevê-se o ordálio do julgamento da mulher por meio da água do rio Eufrates (Hammurabi n.132; apud BOUZON, 1987, p. 141): Apsu, deusa das águas, pronunciava o julgamento e, caso a mulher morresse, era culpada. Porém, o código previa também o recurso a um simples juramento para liberar a mulher (Hammurabi, n.131; apud BOUZON, 1987, p. 141). A legislação no segundo caso dava mais crédito à palavra da mulher. Em Nm 5,11-31, parece haver uma junção de duas leis em uma só. A mulher poderia ser liberada apenas com o juramento, porém o marido tinha o direito de conduzir a mulher para a prova das águas amargas. Pois bem, o marido enciumado conduz a mulher até ao sacerdote e apresenta a oferta (Nm 5,15). Segundo Budd (1984, p. 66), "a introdução da oferta de farinha de cevada (v. 15.18.25-26) traz o ritual para dentro da ideologia do sistema sacrifical pós-exílico a fim de assegurar que o ritual poderia ser realizado apenas pelos sacerdotes de Jerusalém". O marido apresenta a oferta como quem necessita do serviço do sacerdote 
para obter a ajuda de Deus em vista de dirimir a dúvida (GRAY, 1956, p. 50). Observemos que essa mulher está sob o poder do marido e submissa a ele. Aqui o ritual prescreve uma oblação de farinha de cevada sem incenso e sem óleo, o que sublinha o caráter doloroso desta cerimônia (DE VAULX, 1972, p. 95).

Por si só, a oferta de farinha, sem a mistura de incenso e óleo, era oferta dos pobres pela purificação do pecado (Lv 5,11-13). Uma composição justificável, porque não é uma oferta de agradecimento e de louvor, mas sinal de tristeza (CARDELLINI, 2001, p. 471, nota 210). Esta oferta de farinha de cevada é indício de que a mulher é considerada impura (WENHAM, 1985, p. 89). Fílon de Alexandria comenta que essa oferta significaria um sinal negativo: "A farinha de cevada era alimento também dos animais sem razão como símbolo de uma mulher adúltera que não se distingue do animal"; na mesma linha, Gamaliel comenta na Sotah II,1 (apud GRAY, 1956, p. 50). Portanto, a oferta supõe que a mulher seja culpada, ou, como refere Ashley (1993, p. 127), potencialmente culpada. O leitor poderia levantar a questão acerca do motivo dessa oferta de farinha: "Porque não poderia ser suficiente a palavra da mulher junto ao sacerdote para o marido dirimir a dúvida da fidelidade da mulher?" Esse é um dos detalhes que indica o caráter condenatório do ritual. A mulher aqui aparece excluída de participar e deve simplesmente se submeter. Ela é levada pelo homem até o sacerdote, porque o marido não confia na sua palavra, no seu juramento. Então "o homem fará vir sua mulher ao sacerdote" (v. 15). Depois, "o sacerdote a fará vir a mulher diante do SENHOR" (v. 16). São informações que destacam a dependência e submissão da mulher dirigida pelo homem.

Chama a atenção dois termos para esclarecer o significado da oferta (ASHLEY, 1993, p. 127): uma oferta de ciúme, uma oferta de memorial: "Não derramará sobre ela azeite e não colocará sobre ela incenso, porque ela será uma oferta de ciúme. Será uma oferta de memorial, uma lembrança da ofensa" (v. 15). A oferta lembra a ofensa e é memorial da gravidade da ação da mulher. A gravidade do adultério e a condenação recai sobre a mulher, pois o ato é um prejuízo ao marido e a sua honra que precisa ser reparada. A culpa recai sobre a mulher e deve ser reparada com a oferta e lembrada para que a infidelidade não aconteça novamente. $O$ final do ritual volta a dizer que aquela mulher carregará a sua ofensa enquanto o marido ficará livre (v. 31). Não se fala de ordálio no caso de suspeita de adultério do marido. Em caso de adultério, diversa é a legislação do Deuteronômio. Nesse caso, homem e mulher são penalizados quando apanhados em flagrante adultério (Dt 22,22). Porém a legislação no caso de suspeita de adultério só existe em relação a mulher, pois era considerada como propriedade do homem, parte da sua casa. Não havia uma instrução no caso de suspeita de adultério do marido. 


\subsection{Ação do sacerdote em nome de SENHOR}

A ação do sacerdote aparece em todo texto, em ações principais, na preparação de todo ritual do ordálio. É possível observar, nas leis sacerdotais, como a passividade da mulher é destacada com o uso dos verbos no hifil, com sentido causativo. O texto destaca a ação do marido que "fará se aproximar" (v. 16), "colocará de pé diante do SENHOR" (v. 18) (SHECTMAN, 2010, p. 492, nota 34). Depois, toma a água santa, e somente o sacerdote prepara a mistura (v. 17). Depois, solta os cabelos da mulher (v. 18b). Cabelos soltos relembra a vergonha e o sofrimento, caso fosse culpada. Indica também sua potencial impureza, como um leproso que devia andar descabelado (ASHLEY, 1993, p. 129; CARDELLINI, 2001, p. 472). Depois, o sacerdote coloca em suas mãos a oferta de alimentos (v. 18b), faz a mulher jurar (v. 19a.21a) e explica-lhe as consequências do juramento de maldição (v. 21b) e ainda escreve no livro (v. 23a) (KNIERIM; COATS, 2005, p. 80). O detalhe importante é que o sacerdote fará a mulher vir diante do SENHOR (v. 15). Amzallag e Yoná (2017, p. 387) observam, aqui, evidências do contexto Javista de todo ritual: "Isso é revelado pelo fato que a cerimônia se realiza no santuário do Senhor, porque a oferenda é feita ao Senhor, pelo uso da água sagrada e pelo nome do Senhor mencionado em todo texto. Até mesmo no v. 18 é especificado que todo processo ocorre sob a autoridade de SEnHor". Da mesma forma Daniel Miller (2010, p. 5-16), argumenta que o ritual é Javista, pois é realizado diante de SENHOr e administrado pelo sacerdote. A palavra ל כאן (kohen) aparece treze vezes no texto (v. 15.16.17.18.19.21.23.26.30); o tetragrama יחוֹ] (YHWH), sete vezes. O tetragrama é encontrado uma vez nos v. 16.18.25, enquanto no v. 21 aparece duas vezes e, justamente, nas palavras do sacerdote proferindo as consequências do ordálio como ação divina: "O SENHOR te entregue por maldição", "quando o SENHOR entregar tua coxa caindo[...] para que caia a coxa". Além disso, o ritual acontece na morada do Senhor. Ali, o sacerdote fará a oferta ao Senhor. Portanto, toda ação resulta num rito sagrado, o que dá legitimidade à ação sacerdotal como vinda do SENHOR. A mulher permanece passiva, pois é conduzida em todos os momentos e a única vez que fala é para aceitar com resignação, o que pode acontecer de mal, dizendo duas vezes: “Amém! Amém!" (v. 22).

Esses dados caracterizam o rito de julgamento, cujo resultado vem de Deus. Nota-se a visão androcêntrica, pois a mulher é conduzida pelo homem em toda a preparação do ordálio. $O$ ritual é realizado para dirimir a dúvida do homem ciumento, às custas de expor a mulher a um risco. Bem destacaram Amzallag e Yoná (2017, p. 385):

A essência de um ordálio é expor a pessoa suspeita a uma situação de perigo. Se o ordálio da água no código de Hammurabi realmente mata a mulher suspeita, o perigo inerente de beber o copo de água, necessáriamente transforma a prescrição do sotah em ordálio de veneno. Nesse contexto o autor assume que a água santa básicamente não era saudável e imprópria para beber. 


\section{Hermenêutica: formas de violência contra a mulher}

O objetivo, nesta análise, é mostrar as várias formas de violência contra a mulher, seja física ou moral. Ela se destaca na ação do homem, que denuncia apenas por suspeita sem provas objetivas e, especialmente, nas consequências do ordálio, no corpo da mulher, ao longo de sua vida. Não se tem informações que essa espécie de julgamento tenha acontecido nos tempos da composição do relato. No entanto, a hermenêutica aqui realizada é crítica, pois revela a ideologia legitimadora de um julgamento que, em última instância, tem o objetivo de salvaguardar a honra do marido ciumento. Assim, o ordálio era realizado com base na dúvida, e não na certeza. A lei condena a mulher, sem provas, a um teste que coloca em risco sua integridade física e moral. Na mentalidade jurídica na Mesopotâmia, era legítimo o marido ciumento levantar suspeita de sua mulher, porém não era suficiente para incriminar a mulher suspeita (LAFONT, 1999, p. 267).

\subsection{Fazer beber das águas amargas}

O texto menciona duas vezes a ação do sacerdote: "fará beber as águas" (v. 26-27). Essas águas aparecem também nos vv. 18.19.23.24 e tiveram diferentes interpretações, ${ }^{10}$ com uma hermenêutica que não contempla a situação da mulher obrigada a ingerir essa mistura. Os comentários clássicos veem como uma poção mágica. A adição de um pequeno pedaço do rolo escrito na água também tem sido interpretada como um substituto israelita de um componente pagão de tal prática mágica. No Tibet, ingerir um papel no qual um feitiço ou superstição era escrito, era um meio de curar a doença (GRAY, 1956, p. 54). Essa posição mágica é questionada por Amzallag e Yoná (2017, p. 386-387) com base no texto, pois a poção já é chamada água que traz a maldição no v. 22, antes do acréscimo do pedaço do livro escrito na água (v. 23). No v. 23, o livro é para ser acrescentado à água qualificada como "amarga". Isso confirma haver um componente ativo já presente na mistura antes de introduzir o fragmento escrito. Sem contar outros elementos, como o pó do pavimento do santuário, que, segundo a interpretação aqui proposta, é um componente suspeito. A mulher beberá essa mistura sem ter conhecimento de sua composição, porém, o sacerdote sabe dos perigos a que a mulher é submetida e atribui o resultado a uma revelação de Deus. Assim, o ritual possui legitimação divina e, que, em nenhum momento, será questionado pela pessoa acusada. $\mathrm{O}$ fato de a mulher suspeita ser conduzida coercitivamente a beber essa mistura e a

\footnotetext{
${ }^{10}$ Cardellini (2013, p. 249) no excursus n. 12 discute várias interpretações: "águas da convicção, que amaldiçoam" (Septuaginta), "águas do julgamento" "águas do oráculo" pois visa a dar a resposta sobre a culpa ou inocência da mulher, "águas da disputa", no sentido de uma água que esclarece dúvida.
} 
pronunciar um juramento caracteriza uma ação violenta que se prolongará depois nos efeitos danosos no corpo da mulher.

Com razão, Wenham (1985, p. 87-88) questionava essas ações do ordálio pelas águas amargas. Diante desse texto, o leitor ficará imaginando: porque um juramento não era suficiente por si mesmo, sendo necessário passar por essa terrível prova? Deus não teria respondido à oração do sacerdote para inocentar a mulher sem recorrer a esse ritual perigoso? Será que esta cerimônia não dá a entender uma noção de um Deus sujeito a manipulação humana ou de uma crença não científica ${ }^{11}$ na eficácia da água amarga? São questões que emergem a partir da análise do texto.

\subsection{Efeito abortivo das águas da maldição}

Sobre o provável efeito abortivo do ordálio das águas amargas, as interpretações recentes divergem em relação à interpretação tradicional. De um lado, Milgrom, por exemplo, põe em dúvida se o conteúdo da bebida ingerida produzia algum sintoma nocivo na mulher. Segundo ele, o objetivo do rito era provar a inocência da mulher e evitar o seu linchamento. Milgrom parece não questionar os limites do ordálio, pois sua interpretação, como a de outros autores, limita-se ao sentido do ordálio no contexto literário e cultural do autor, e não avança para uma hermenêutica crítica. Não questiona porque esse ritual de ordálio era aplicado somente à mulher no caso de suspeita de adultério e não era aplicado aos que cometiam outros delitos. ${ }^{12}$

Do outro lado, para fundamentar a hipótese do possível efeito abortivo das águas da maldição, será necessário avançar para o estudo da sua composição. Estudos recentes, como os de McKane, Cardellini, Feinstein, Amzallag e Yoná têm interpretado o termo "amargo" como tóxico. Assim, o componente da água não teria efeito mágico, mas previsível. Segundo Mckane (1980, p. 478), águas que amaldiçoam são águas que amaldiçoam com veneno. A mistura da água com o pó e a tinta da escrita no rolo tornariam a água venenosa (VONNORDHEIM, apud CARDELLINI, 2013, p. 249). Uma interessante composição das "águas amargas", em Nm 5,11-31, é que elas não são apenas intragáveis, mas sobretudo "amargas" nos seus efeitos (v. 24.27). Por isso, na descrição das "águas amargas", acentua-se o aspecto punitivo do ritual, com ênfase na descrição das águas que

\footnotetext{
${ }^{11}$ Reconhecendo que a referência ao "caráter científico" do experimento da água amarga é anacrônico, isto é, na época do texto não se conhecia este conceito classificado como "científico". ${ }^{12}$ Maiores informações: JACOB, M. The case of the suspected Adultress, in the creation of Sacrad literature; apud Richard Elliot Friedman. Why is this case diferent from all other cases? Essays in honour of H.G.M. Williamson on the occasion of his sixty-fifth Birthday. In: PROVAN, I., BODA, M., (Eds) Let us go up to Zion. Leiden: Bril, 2012, p. 372. Disponível em: https:www.academia.edu/the sotah. Acesso em: 26 jun. 2019.
} 
amaldiçoam (FEINSTEIN, 2012, p. 304). Mediante o estudo da composição das águas, nota-se que o ritual não é simplesmente um ordálio que opera por efeitos mágicos, mas por efeitos previsíveis do componente venenoso misturado nas águas que são de maldição.

De acordo com Amzallag e Yoná (2017, p. 338), é preferível considerar a presença de um componente ativo na mistura com um efeito não apenas psicológico, mas físico, e de graves consequências. Conforme o v.17, a preparação da mistura consiste na dissolução do ע̦ ('aphar) na água. Amzallag e Yoná $(2017$, p. 389) trabalham a hipótese de que o componente

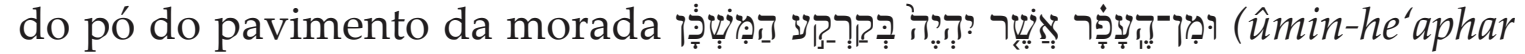
'asher yihyeh beqarqa' hammishkan) (v. 17) possui um componente mineral. Citando Jó 28,2, lê-se: "Ferro é extraído do ע̦ עִ ('aphar), da rocha é derra-

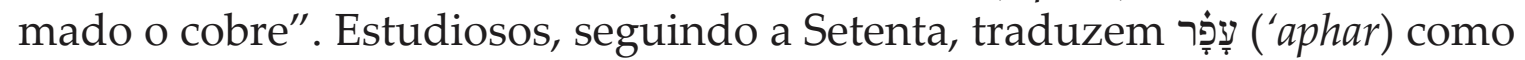
pó, em vez de mineral. Porém, em outro texto, em Nm 5,17, y̦ ('aphar) pode significar mineral, pois o ferro era derretido do mineral e não do pó (Jó 28,2.6). ${ }^{13}$ A designação de עִ עִ ('aphar) poderia ser contestada pelo fato de que dificilmente seriam encontrados minerais no pavimento do tabernáculo ou no santuário onde o pó foi retirado. No entanto, Amzallag e Yoná (2017, p. 390) argumentam, no texto, que o uso dos verbos no futuro é significativo: "o sacerdote tomará a água santa", "do pó que será do pavimento do tabernáculo", "o sacerdote tomará e colocará na água". O futuro é usado em verbos para instruir uma prescrição (quando x ocorrer, você fará como y). Assim, a poção preparada pode ter elementos não necessariamente presentes no santuário, mas trazidos de fora e misturados na poção a ser ingerida.

Observam ainda as autoras que:

O mineral metálico era moído antes de ser derretido. Assim a presença de mineral moído no pó do pavimento do santuário implica em que culto do metal era praticado lá. Tal ocorrência, em relação aos israelitas, não é relatada na Bíblia. No entanto, uma tenda santuário tem sido identificada em área de exploração do cobre em Timná (Sul do Arabá) (2017, p. 390).

Isso significa que um estrato de pó do pavimento do santuário foi en-

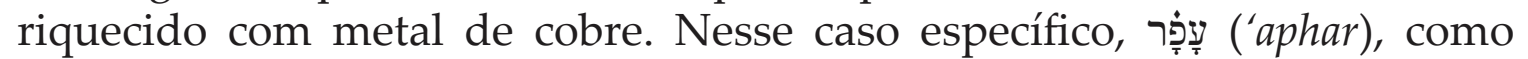
mineral e pó, designa a mesma realidade: fina camada de mineral de cobre esmagado. Isso, em contato com componente do pó de terra, torna-se tóxico e provoca perturbações graves (AMZALLAG; YONÁ, 2017, p. 390). Tão logo uma quantidade de עִ עִ ('aphar) é misturada com água (v. 17), a mistura causa potencialmente a maldição (v. 18), sem qualquer necessidade de rito de encantamento ou necessidade de invocar o SenHor. Com esses

${ }^{13}$ Essa designação do 'aphar como mineral metálico aparece também em Gn 3,14; Is 34,9; 41,2; 65,25; Ez 26,12; Pv 8,26; Jó 22,24; 30,6. 
argumentos, Amzallag e Yoná (2017, p. 394) argumentam que os efeitos da ingestão desses componentes tóxicos são abortivos. Portanto, causam uma violência física e psicológica de efeitos a curto prazo.

Estas autoras, Amzallag e Yoná (2017, p. 396), reúnem argumentos de que a poção induz ao aborto antes que a esterilidade. Parte-se do princípio do significado de עִ עִ ('aphar) (v. 17), como comentado acima. Essa composição de metal de cobre seria o sal de cobre que produz um rápido efeito abortivo nos primeiros estágios da gravidez (AMZALLAG; YONÁ, 2017, p. 396). Em doses maiores, o sal de cobre provoca intoxicação aguda, e fortes desordens psicológicas. Isso poderia ser letal (SAVARU et al. 2007; ROYCHOUDHURY et al., 2016, p. 12-13). ${ }^{14}$

O texto relata que a ingestão das águas amargas fará "cair a coxa e inchar o ventre". Essas consequências são declaradas pelo sacerdote à mulher no v. 21, repetidas no v. 22, e mais uma vez no v. 27. E na presente análise, portanto, é mais provável que o efeito do ordálio "inchar o ventre" signifique gravidez e "cair a coxa" signifique aborto. Com efeito, conforme o v. 13, se outro homem "deitou nela uma camada de sêmen", teve uma relação completa, o que possivelmente resultaria em gravidez. Nesse caso, a expressão "cair a coxa" é eufemismo para o aborto provocado pelas águas tóxicas. Amargura e maldição são o primeiro resultado da bebida. Metaforicamente, significam o sofrimento a partir do interior do corpo, um sofrimento físico, psicológico e moral, que irá perdurar.

O termo "inchar o ventre" parece ser a provável "descrição de gravidez, antes de qualquer outro infortúnio" (FRYMER-KENSKY, 1984, p. 20). Portanto, não parece ser sinal de alguma forma de esterilidade, como interpreta Ashley (1993, p. 133), uma vez que o texto afirma: "se a mulher não se contaminou, será inocente e conceberá uma descendência" (v. 28). Se a gravidez foi resultado da relação da mulher com outro homem, a gravidez seria prova da culpa da mulher. Porém, o homem que levanta suspeita da infidelidade da esposa não tem conhecimento de sua gravidez e é incerto também se ela foi causada pelo marido ou por outro homem (FRIEDMAN, 2012, p. 378-379). O marido não tem argumentos para provar a suspeita de adultério da esposa. O que chama a atenção é a situação dramática da mulher, seja ela culpada ou inocente. Sofrerá os efeitos da ingestão das águas amargas e terá sua imagem difamada pela acusação de adultério.

\footnotetext{
${ }^{14}$ As autoras Nissim Amzzalag e Shamir Yoná baseiam suas afirmações em pesquisas recentes da medicina: ROYCHOUDHURY, S. et al. Copper-induced changes in reproductive functions: in vivo and in vitro effects. Physiological Research, n. 65, v. 1, p. 11-22, 2016; e SAVARU, K. et al. Acute Ingestion of Copper Sulphate: A review on its Clinical Manifestations and Management, Indian Journal Critical Care Medicine Luknow- India, n. 11, p. 74-80, 2007.
} 


\subsection{A mulher carregará a culpa}

O julgamento por ordálio alcança o seu clímax com a possível demonstração da culpa ou inocência da mulher. Destaca Harrison (1992, p. 115), pelos efeitos danosos, "mesmo se a mulher for inocente, o prospecto do sofrimento físico e a condenação espiritual, estaria longe de ser suportado, refletindo sobre sua integridade moral". Seria uma condenação! A mulher difamada "se tornará maldição no meio do seu povo" (v. 27). Essa violência é desencadeada pela realização do ritual do ordálio com a resposta da mulher compelida a falar "Amém! Amém! "diante do sacerdote (v. 22). Essa repetição enfatiza, além do mais, a seriedade do juramento (ASHLEY, 1993 , p. 133) e, especialmente, o assentimento da mulher submissa que aceita como adequado o que acontecerá. ${ }^{15}$

O v. $31 \mathrm{~b}$ aplica-se somente se ela é culpada de adultério. Observa Sarah Shectman (2010, p. 488-490) que esperaríamos uma afirmação de que ela poderia ser inocente, no entanto, o texto indica que "ela carregará a sua culpa", como parece implícito no v. 15, na oferta como memorial da culpa. É possível que esse acréscimo se refira à realização do juramento e aos efeitos da água ingerida do ordálio. Assim, o v. 31 reitera a ideia de que a mulher carrega sua culpa através da punição física, e além da punição física, a mulher carregará também sua culpa no futuro (SHECTMAN, 2010, p. 488).

Um exame da frase "carregar a culpa", no contexto sacerdotal mais amplo, determina seu uso nesse texto. "Carregar a culpa" aparece 20 vezes no Pentateuco, principalmente em material sacerdotal, com possibilidade de significar "culpabilidade"; e, com frequência, usado para pecados involuntários, como na coleção de casos em Lv 5. Em alguns desses casos, se a mulher não se tornou impura, então ela será inocente. Será, então, livre da culpa e conceberá uma descendência. A expressão refere-se a pecados dos quais não há posterior punição ou ato de expiação, significando que não é culpa plena. Essa interpretação ignora a repercussão da denúncia contra a mulher e a ofensa irreparável de sua honra, por ter sido levada pelo homem à presença do sacerdote, ter sido submetida ao rito do ordálio e ao juramento sob imprecação. O ponto de vista do redator final de Números é o de salvaguardar a honra do homem. Conforme Budd (1984, p. 65), esse versículo afirma que o homem é livre de culpa mesmo se sua suspeita tenha sido provada falsa.

\subsection{Ritual do ordálio se torna Torah (v. 29-30)}

A apresentação do ritual é concluída reafirmando que é uma "instrução dos ciúmes" (v. 29) a ser seguida pelo sacerdote (v. 31). A fórmula "esta

\footnotetext{
15 "Amém, Amém" (Nm 5,22) não parece ser "uma solene determinação da mulher de declarar sua inocência" como destaca a Mishna, Sotah $(2,5)$.
} 
é a Lei" é característica do escritor sacerdotal e usada normalmente para introduzir uma Lei (Nm 6,13.21; Lv 6,2.7.18; 7,1.11.37; 11,46) (BOSCI, 1976, p. 69). Numa perspectiva feminista, a preocupação do ritual em destacar o rito como "Torah" visa "compensar a falta de evidência da acusação e prover uma justificação para a prescrição do ritual do ciúme" (BRITT, 2007 , p. 3). Pelo que parece, portanto, esse também é indício evidente que desautoriza a práxis do ritual do ordálio. Além do mais, como provar a inocência ou culpa da mulher mediante um ritual de julgamento que pode causar danos físicos graves e expor a pessoa julgada a um grave perigo de vida? O texto conclusivo é paralelo aos v. 14.15, retomando o motivo do ritual: a suspeita de infidelidade e o ciúme. O homem, nesse caso o marido que submeteu a mulher ao ordálio, não carrega nenhuma culpa, mesmo que sua suspeita de adultério da mulher seja provada sem fundamento. Diferente nos escritos de Mari, por exemplo, o marido que fizesse falsa acusação caluniando sua mulher seria queimado (DAVIES, 1995, p. 57).

A julgar, segundo Dt 19,15-21, o marido que levantou suspeita falsa deveria ser punido por falso testemunho! Certas questões são levantadas: por exemplo, em Dt 22,13-31, prevê-se castigo ao marido por caluniar a esposa dizendo que não era virgem quando casou. Se a acusação dele for verdadeira, a mulher será apedrejada. O Código de Hammurabi (n. 131; apud BOUZON, 1987, p. 141) previa que era suficiente o juramento da mulher acusada sem ser pega em flagrante para dirimir a dúvida. A palavra da mulher podia ser aceita e o marido a perdoava. Mas há também a lei de que o marido, no caso de sua mulher ser acusada de adultério, mesmo sem provas, teria sua mulher submetida ao ordálio pelas águas, sendo jogada no rio (Hammurabi, n.132; apud BOUZON, 1987, p. 141). Em Nm 5,11-31, temos a junção do juramento com o ordálio ${ }^{16}$ sem opção para a mulher, o que caracteriza a violência do julgamento. Como destaca Kakenfeld (1995, p. 35), a legislação tão severa nesse caso é focada apenas nos direitos do homem e suas prerrogativas. O ritual destaca em Israel a presunção de que qualquer relação sexual fora do casamento é uma ofensa apenas contra o homem. Se o marido de mulher casada tem relação fora do casamento, não há recurso legal para a esposa reclamar. Mas se o marido é apanhado em adultério com mulher casada e ambos forem pegos em flagrante, os dois devem morrer (Dt 22,22; Lv 20,10).

\footnotetext{
${ }^{16}$ Jeon (2007, p. 181-207) sustenta que o texto seja uma norma originária sobre o ordálio com água unido a um estrato redacional mais recente que trataria do rito do juramento imprecatório. Os estudos diacrônicos se fundam em certas rupturas no texto (v. 21), o que levou à conclusão de que ao menos dois relatos foram reunidos. Conforme comenta Noth, (1966, p. 45-46), "são juízos de Deus difíceis de separar". Por isso é melhor abordar o texto na sua forma final.
} 


\section{Considerações finais}

Destaca-se como resultado desta pesquisa a constatação do quanto é inconsistente e irracional a aplicação da lei do ordálio em Nm 5,11-31. Eis os motivos principais:

$1^{\mathrm{o}}$ - toda estrutura do relato legitima a autoridade do homem e é voltado a sanar a dúvida do marido enciumado, para que sua imagem fique preservada, enquanto a mulher carrega sobre si a culpa. Somente ela é difamada no meio da comunidade.

$2^{\underline{o}}-$ o julgamento torna-se quase uma execução, pois a mulher apenas suspeita de infidelidade. Sem provas contra ela, é levada de forma coercitiva diante do sacerdote e é obrigada a ingerir uma mistura que coloca em risco a própria vida. A mistura ingerida pode provocar o aborto, esterilidade e até a morte.

$3^{\mathrm{o}}-$ o ritual do ordálio serve como controle seguro sobre os corpos das esposas por parte dos maridos. Essa ideologia é reforçada pelas regras de pureza vindas do próprio Deus por meio de Moisés. Nessa visão, a infidelidade é considerada uma impureza. E toda dúvida sobre culpa ou inocência da mulher denunciada deve ser redimida em vista da purificação. Soma-se a isso o fato de que a mulher deve se submeter ao ordálio e ao juramento. E esse ritual é litúrgico, sendo realizado com a ação do sacerdote no santuário.

A hermenêutica do texto vai além do sentido contextual do relato com objetivo de purificação conforme o livro dos Números. Essa ótica de leitura desconstrói a visão tradicional que interpretava o ordálio no seu sentido estrito em vista de resolver um litígio ou esclarecer uma dúvida. O ordálio é, na realidade, um ritual sagrado que legitima práticas de violência contra a mulher. Será lembrado enquanto memorial como advertência às mulheres para não traírem e, em favor dos maridos, como uma instrução do que fazer

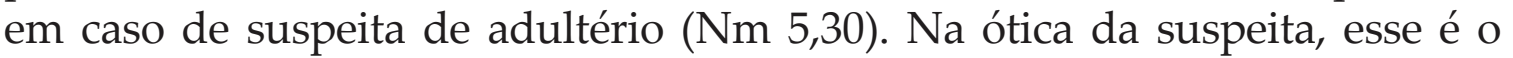
sentido e objetivo do relato. Tanto a análise dos personagens, das ações e reações, como a hermenêutica revelaram formas mais evidentes de violência contra a mulher. Destaca-se a violência física: o beber das águas amargas da maldição e suas consequências abortivas e de esterilidade; violência moral: difamação do nome da mulher que carregará a culpa, violência psicológica ao ser intimada a comparecer diante do sacerdote e prestar juramento.

O ritual aplicado já pressupõe a culpa e a impureza da mulher: "Ela carregará sua culpa" (Nm 5,31). Eis um detalhe sutil que revela a ótica do autor sacerdotal. Certos elementos estilísticos do texto caracterizam-no como uma violência narrada. Eles enfatizam o caráter punitivo do ritual em forma crescente: "águas amargas", depois "águas amargas da maldição"; e mais a oferenda que invoca a lembrança da iniquidade, seguida do 
juramento, a exposição da mulher publicamente, que "se tornará maldição

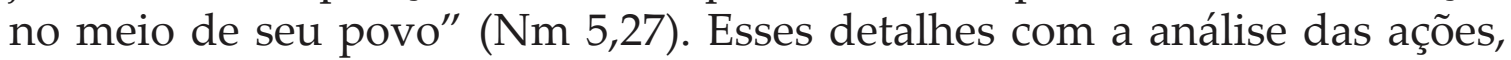
dos personagens, da reação, seguidos da hermenêutica, são a contribuição desse estudo na interpretação do ordálio no livro dos Números. O caráter androcêntrico do ritual destaca-se na ação do marido e do sacerdote em todo ordálio, enquanto a mulher permanece passiva. Ela se submete a ingerir das águas amargas sem ter conhecimento de sua composição. Menciona-se o fato de que o marido que levantou a suspeita não carrega nenhuma culpa mesmo que a suspeita da mulher seja provada como sem fundamento. De fato, não havia instrução no caso da suspeita de adultério do marido. Essas constatações ajudam a entender o contexto do ritual as consequências de sua aplicação no caso de suspeita de adultério da mulher.

Para concluir, a prova do ordálio das águas amargas para dirimir uma dúvida é uma alternativa tão severa quanto a pena de morte prescrita para os adúlteros apanhados em flagrante (Lv 20,10; Dt 22,22). A violência do ordálio, enfim, se revela no método de julgamento; está na forma de culpabilizar a mulher num processo baseado na suspeita e não nos fatos. A violência está encrustada na lei do ordálio instituído como memorial. No judaísmo, o tratado da Mishna, no "Sotah", interessou-se em preservar a lembrança perdida desse rito. Porém acrescenta que no final ele foi abolido e declarado impraticável. ${ }^{17}$

No entanto, se o criticado rito do ordálio foi abolido, as formas de violência contra a mulher se perpetuam: a discriminação, violência psicológica, violência física e, mais grave, o feminicídio. Mesmo em países que se dizem mais "evoluídos", a violência, se não é tão explícita, continua velada: ela é endêmica e subjaz numa cultura ainda androcêntrica e machista em muitas regiões. A violência não pode ser calada e precisa ser denunciada, uma vez que se supõe do povo o conhecimento e consciência da dignidade e dos direitos do ser humano: todos são "imagem e semelhança de Deus".

\section{Referências}

AMZALLAG, N.; YONÁ, S. The Kenite. Origin of the Sotah Prescription (Numbers 5,11-31). Journal for the study of the Old Testament, Los Angeles, v. 41, n. 4, p. 383-412, 2017.

ARTUSO, V. A teoria documentária do Pentateuco: aplicação e limites na análise de Nm 16-17. Atualidade Teológica, Rio de Janeiro, v. 16, n. 41, p. 279-300, 2012.

${ }^{17}$ Sobre o ordálio na Mishna: DESTRO, Adriana. Il caso di gelosia. Antropologia del rituale di Sotah, Il Mulino: Bologna, 1989. 
ASHLEY, T. R. The Book of Numbers. Michigan: Eerdmans Publishing, 1993.

A BIBLIA. Pentateuco. Direção editorial Flávia Reginatto, Vera Ivanise Bombonatto. Tradução do hebraico, introdução e notas. Elizangela Chaves Dias (Gn e Lv) Fabrizio Zandonadi Catenassi (Nm introdução e notas), Leonardo Agostini Fernandes (Dt) Matthias Grenzer (Ex) Vicente Artuso (Nm tradução), São Paulo: Paulinas, 2021.

BOSCI, B. G. Numeri. Roma: Paoline, 1976.

BOUZON, E. O Código de Hammurabi: introdução, tradução do texto cuneiforme e comentários. Petrópolis: Vozes, 1987.

BRICHTO, H. C. The case of the sothah and a Reconsiderations of Biblical Law. HUCA, n. 46, p. 55-70, 1975.

BRITT, B. Male Jealously and the suspected Sotah. Toward a conter-reading of Numbers 5,11-31. The Bible and critical theory, New Zealand, v. 3, n. 1, 05.1-05.19, 2007.

BUDD, J. P. Numbers. Waco, Texas: General Editors, 1984.

CARDELLINI, I. I sacrifici del l'Antica Alleanza. Milano: Paoline, 2001.

CARDELLINI, I. Numeri 1,1-10,10: nuova versione, introduzione e commento. Milano: Paoline, 2013.

DAVIES, E. W. Numbers. London: William B. Eerdmans Publishing Company, 1995.

DE VAULX, J. Les Nombres. Paris: J. Gabalda et Cie Éditeurs, 1972.

DELEUZE, G.; GUATTARI. Anti-Oedipus: Capitalism and Schizophrenia. Minneapolis: University of Minnesota Press, 1983.

DESTRO, A. Il caso di gelosia. Antropologia del ritual di Sotah. Il Mulino: Bologna, 1989.

DOUGLAS, M. Nel deserto: la dottrina della contaminazione nel libro dei Numeri. Bologna: Centro Editorial Dehoniano, 2001.

FEINSTEIN, E. L. The "Bitter Watters" of Numbers 5,11-31. Vetus Testamentum, Leiden, n. 62, p. 300-306, 2012.

FERRASIN, M. M. Ordálios, historiografia e os escritos episcopais de Agobardo e Incmar. Anais do XXVII Simpósio Nacional de História. ANPUH, São Paulo, Julho, 2011.

FISHBANE, M. Accusations of adultery: a study of Law and scribal practice in Numbers 5,1-31. HUCA, n. 45, p. 25-45, 1974.

FRIEDMAN, R. E. Why is this case diferent from all other cases? Essays in honour of H.G.M. Williamson on the occasion of his sixty-fifth Birthday. In: PROVAN, I., BODA, M., (Eds) Let us go up to Zion. Leiden: Brill, 2012. p. 372. Disponível em: https:www.academia.edu/the sotah. Acesso en: 26 de junho de 2019.

FRYMER-KENSKY. "The strange case of the suspected Sotah" (Nm 5,11-31). Vetus Testamentum, Leiden, n. 34, p. 11-26, 1984.

GESENIUS, W.; KAUTZSCH, A. Gesenius' Hebrew Grammar. Second English edition revised in accordance with the twenty eighth German edition (1909) by A. E. Cowley. London: Oxford University Press, 1910. 
GRAY, G. B. Numbers: a critical and exegetical commentary. Edinburgh: T. Clark LTD, 1956.

HARRISON, R. K, Numbers: an exegetical commentary. Michigan: Grand Rapids, 1992.

JEON, J. Two Laws in the sothah passage (Nm 5,11-31). Vetus Testamentum, Leiden, n.57, p. 181-207, 2007.

KAKENFELD, K. D. Journeying with God. International Theological Commentary. Edinburgh: B. Eerdmans Publishing, 1995.

KNIERIM, R. P.; COATS, G. W. Numbers. The forms of the Old Testament Literature. Michigam, Cambridge: Grand Rapids, 2005.

LAFONT, S. F. Droit et Justice dans la Antiquité orientale. Contributions à 1' etude du droit penal au Proche-Orient ancient. In: Orbis Biblicum et Orientalis, n. 165. Universitats verlag - Vandenhoeck \& Ruprecht: Fribourg-Gottingen, 1999. p. 562.

LEVINE, A. B. Numbers 21-36: a New Translation with introduction and commentary. New York-London: Doubleday, 2000.

LÉVY-BRUHL, L. A mentalidade primitiva. São Paulo: Paulus, 2008.

MARFO, E. K. Study of Numbers 5,11-31 and the Ancient Near East Mari and the Hammurabi codes. Journal of Religious and Theological Studies, Noyam-Ghana, v. 1, n.1, p. 144-186, 2017.

MCKANE, P. Trial by Ordeal and the cup of Wrath. Vetus Testamentum, Leiden, n. 30, p. 478-487, 1980.

MIGLIO, A. Ordeal, Infidelity, and Prophetic Irony in Jeremiah 2,1-9. Scandinavian Journal of the Old Testament, n. 24:2, 2010, p. 222-234; Published online: 11 jan 2011. Disponível em: https://doi.org/10.1080/09018328.2010.527076. Acesso em: 20/01/2019.

MILLER, D. Another look at the magical ritual for a suspected adulteress in $\mathrm{Nm}$ 5,11-31. Magic, Ritual, and Witchraft. Pensilvânia, v. 5, n.1, p. 1-16, 2010.

MILGROM, J. The case of the suspected Adultress, in the creation of Sacrad literature; Apud: Richard Elliot Friedman. Why is this case different from all other cases? Essays in honour of H. G. M. Williamson on the occasion of his sixty-fifth Birthday. In: PROVAN, I., BODA, M., (Eds) Let us go up to Zion. Leiden: Bril, 2012. p. 372. Disponível em: https: www.academia.edu/the sotah. Acesso em 26/01/2019.

NOTH, M. Numbers. London: SCM Press, 1966.

PRITCHARD, J. B. (Ed.). Ancient Near Eastern Texts Relating to the Old Testament with supplement. Princeton \& New Jersey: Princeton University Press, 1969.

ROYCHOUDHURY, S. et al. Copper-induced changes in reproductive functions: in vivo and in vitro effects. Physiological research, Prague, v. 65, n. 1, p. 11-22, 2016. Disponível em: http://www.biomed.cas.cz/physiolres/pdf/65/65_11.pdf. Acesso em: 09/10/2021.

MORELL, O. I. R. Las aguas amargas de la mujer: la ordalia de los celos en el rabinismo. Espanha: Verbo Divino, 1999. 
SAVARU, K. et al. Acute Ingestion of Copper Sulphate: a Reviewon its Clinical Manifestations and Management. Indian Journal Critical Care Medicine, New Delhi, n. 11, p. 74-80, 2007.

SHECTMAN, S. Bearing Guilt in Numbers 5,12-31. In: STACKERT, J; PORTER, B.N. Wright, D. C. (Eds). Gazin on the deep: Ancient Near Easter, Biblical and Jewish Studies in honour of Tzvi Abusch. Tethesda: CDL Press, 2010. p. 479-493. SCHÖKEL, L. A. Dicionário Bíblico Hebraico-português. São Paulo: Paulus, 1997.

SCHOTTROFF, L.; SCHROER, S.; WACKER, M-T. Exegese Feminista. Resultados de pesquisas bíblicas a partir da perspectiva de mulheres. São Leopoldo: Aste, CEBI, Sinodal, 2008.

WENHAM, J. G. Números: introdução e comentário. São Paulo: Vida Nova; Mundo Cristão, 1985. (Cultura Bíblica).

Artigo submetido em 02.10.2020 e aprovado em 28.09.2021.

Vicente Artuso é Doutor em Teologia Bíblica, pela PUC-Rio. Mestre em exegese bíblica, pelo Pontifício Instituto Biblico de Roma. Professor no Programa de Pós-Graduação em Teologia da PUCPR e do Studium Theologicum Claretiano de Curitiba. Orcid.org/0000-0003-3036-1774. E-mail: vicente.artuso@pucpr.br

Endereço: Rua Manoel Ribas, 966

Freis Capuchinhos

Mercês

80810.000 Curitiba - PR 